\section{All in the mind?}

\section{John C. Marshall}

The Oxford Companion to the Mind. Edited by Richard L. Gregory. Oxford University Press: 1987. Pp. 856. Hbk £25, $\$ 49.95$.

From "abacus" to "Zeno of Elea", by way of "masochism" and "metempsychosis", this massive compilation really does contain something for everyone. In emulation of that well-known psychologist Scheherazade, The Oxford Companion to the Mind contains 1,001 entries. These range from brief one-liners ("Analogue. See Digital") to substantial essays on asylums, colour vision and table manners. The contributors (and the distinguished folk they discuss) are a similarly motley crew. Psychologists, physiologists, philosophers, psychiatrists and pedagogues take the lions' share, although anthropologists and anatomists, computer scientists and criminologists, linguists and logicians, neurologists and neurochemists all contribute to the feast ... to say nothing of the television astronomer and one or two theologians.

Clearly, then, Richard Gregory's Mind is a catholic Church, and one dreads to think of the amount of time and patience that he has devoted to the project. Indeed the decade or more required to organize the 200 or so contributors is such that quite a number of them have died in the interval between writing and publication. Nevertheless, a reviewer must ask whether the effort was worth it. There is, of course, no point in nit-picking; with an enterprise of this scope there is no way in which an editor can please all of the people all of the time. But one can ask to whom this Oxford opus will be a companion, and one should worry about the overall picture of mental life that is being presented.

Unsurprisingly, the best articles are those that discuss a substantive body of sober scientific work. Many of these are concerned with the physical substrate of mind in the central nervous system. Thus Colwyn Trevarthen (on brain development), Marcus Raichle (images of the brain in action), Alan Cowey (neuroanatomical techniques) and H.F. Bradford (neurotransmitters and neuromodulators), for example, all contribute useful summaries for the serious student while still allowing that strange creature the 'general' reader to follow what's going on. And there are many other more 'cognitive' articles that are equally good.

Such 'core' topics as language, perception, memory and problem-solving are also well-covered: to pick just a few of the many fine essays, Noam Chomsky writes lucidly on the growth of language within the individual mind/brain; Bela Julesz outlines his theory of (pre-attentional) visual processing as an early warning system; J.A. Deutsch summarizes experimental approaches to the study of learning and memory; and Peter Wason explicates various seemingly trivial logic problems that fox bright graduate students (for nontrivial reasons).

The numerous thumbnail sketches of the great and the good are similarly helpful for anyone who has forgotten (or never knew) that Charles Babbage, who built the first programmable computing machine, also invented the ophthalmoscope; that Golgi (Camillo) was a Lombardian, as well as a stain for

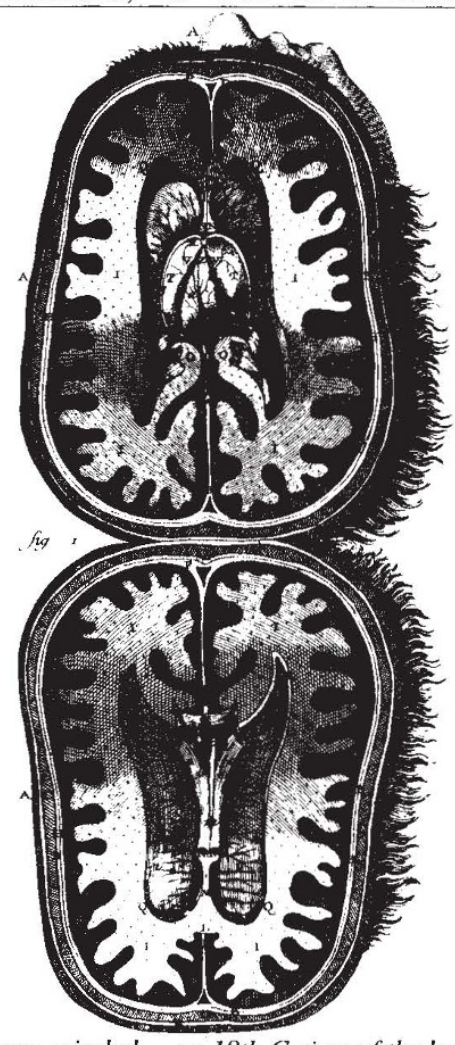

Open-minded - an 18th C view of the brain.

neurons; or that Arthur Schopenhauer was "a lonely and unloved bachelor, befriended only by his poodle Atma". Many of the more informative biographical entries (including those on Kurt Goldstein, Heinrich Kluver and Wilder Penfield) were contributed by Oliver Zangwill, the doyen of British psychology, whose recent death was the loss of a scholar and a gentleman.

The Companion contains no entry between "Platonic forms" and "pleasure centres", the point where one might have expected to see reference to that most serious of all human activities, play. Nonetheless, aesthetic pleasure does find a place in The Mind. The late Richard Jung, a neurologist from Freiburg, has contributed a beautiful and insightful little chapter on art and visual abstraction in which he relates graphic marks to the types of visual representation computed by different physiological mechanisms in the brain; Natasha Spender, a concert pianist, provides a similarly exciting piece on the psychology of music. This article expertly covers music as psychoacoustic stimulus, as perceptual pattern, as formal language, as sensory-motor skill and as emotional experience. A 'reductionist' Natasha Spender is not.

The Companion does, however, contain an essay on reductionism in psychology, albeit not by a philosopher. Rather, the topic is discussed by the (late) Soviet neuropsychologist Alexander Romanovich Luria, who approaches it as a good Marxist: "The explanation of the phenomenon is supposed to lie not in its reduction to single elements but rather in its inclusion in a rich net of essential relations". As Karl said: science should ascend to the concrete, not the abstract. I was grateful for Luria's offering because the philosophers themselves make heavy weather of their supposed contributions to clarity and knowledge in this volume. True, the entries on the classics (Aristotle, Descartes, Plato, Spinoza, for example) are clear and often entertaining; but for the rest there is far too much second-hand 'analytic' philosophy of the sort that clutters up the shelves in academic bookshops. Philosophers of physics, say, are expected to know some physics; why is it that philosophers of mind seem to feel that an afternoon of quiet meditation is a sensible alternative to learning what has actually been discovered about the structure and functions of the mind/brain?

In his autobiography, G.E. Moore wrote: "I do not think that the world or the sciences would ever have suggested to me any philosophical problems". Likewise, Ludwig Wittgenstein (in his notes on Culture and Value): "At bottom I am indifferent to the solution of scientific problems". One suspects that the twentieth-century 'professionalization' of philosophy is, in part, responsible for this sorry state of affairs. Be that as it may, Richard Gregory could have found more philosophers who were prepared to do their homework.

The more theological entries are somewhat better, although a little skimpy given the important role that religion has always played (for good and ill) in humanity's conception of itself. The Reverend O.J.W. Hunkin's piece on religion is calm and thoughtful, and is neatly complemented by Sir Edmund Leach on humanism. Eastern approaches to the mind are particularly well represented, and variations upon Islam abound with copious entries for teachers whose names begin with $\mathrm{Al}$ - or Ibu. Interesting as these pieces are they do not help us to understand the state of mind that currently reigns in the Gulf (and may yet send us all to perdition). Christians and Jews have a leaner time in the Companion - no Hildegard of Bingen or Nachman of Bratslav graces these pages. 
Indeed the only Western mystic we find is that Viennese engineer who was "indifferent to the solution of scientific problems". I hope that the propeller Richard Gregory reports him as designing actually worked.

But the very worst I have left 'til last: the Companion has entries (some of them quite long) under astrology, extra-sensory perception, ghost, levitation, paranormal (this, that and the other), spiritualism and telekinesis. I do realize that many people are keen on such things, but I see no good reason why that attitude should be pampered. Just as the first responsibility of a hospital is to not spread disease, so the first responsibility of a Companion to the Mind is to not encourage superstition. There are plenty of problems awaiting solution before we need concern ourselves overmuch with mysteries. I would happily have swapped all these para-chapters for an extended essay by that truly great student of matter-over-mind, James ("The Amazing") Randi.

John C. Marshall is in the Neuropsychology Unit, part of the Neuroscience Group at the Radcliffe Infirmary, Oxford $O X 26 \mathrm{HE}, U K$

\section{On speaking terms}

\section{J.Z. Young}

Mindwaves: Thoughts on Intelligence, Identity and Consciousness. Edited by Colin Blakemore and Susan Greenfield. Basil Blackwell: 1987. Pp. 525. £19.50, $\$ 24.95$.

RECENT discoveries in neuroscience have introduced new controversies into the problem of how best to speak of the relations between mind and brain. This book provides 32 opinions on the subject and makes a fascinating study of the different approaches of philosophers and scientists. Neuroscientists feel that they have been helped by adopting part of the terminology of communication engineering and computer science, but some philosophers claim that the use of such terms introduces dangerous conceptual confusions into the debate.

The philosopher Peter Hacker and linguist Roy Harris have taken their task to be correction of the mythological language used by physiologists, picking on Frisby, Barlow, Phillips, Zeki and especially as expressed in my own book Programs of the Brain. They object to such terms as 'information', 'coding', 'language', 'mapping' or 'representation' being used in genetics and neuroscience. saying that they are misapplied and may lead to "disastrous equivocations" or misleading metaphors that cannot be tested.

All discussion is helpful but these criticisms show surprisingly little sense of history and are short-sighted and obscurantist. They miss the point that all living things are agents and communication systems. Biology advances in line with technology, applying to human beings and animals the understanding and terminology derived from prosthetic devices that replace or augment our functions. These terms from communication engineering are part of current language. Geneticists, biochemists and neuroscientists find it useful to speak of communication of information by codes and the setting up of representations: most of the contributors to this volume use such words and they are not likely to stop doing so because philosophers insist that these terms should be used only in restricted senses and about whole human persons.

It is worthwhile examining this problem further. The ability to communicate by conventional code signs is characteristic of living things. It provides the information that maintains the pattern of order that allows life to delay the increase of entropy. Signals that transmit this semantic information are indeed parts of the pre-arranged communication systems of genes, hormones and brains. To quote Hacker himself: "A symbolic description is presumably an array of symbols which are so combined as to yield a true (or false) characterisation of a certain aspect of the world. It must be cast in a certain language which has a vocabulary and a grammar". Living things can be said to use symbols in just this way and the points of view of these philosophers obscure this fundamental fact about life. Moreover, the critics imply an unacceptable dualism: they seem not to realize the axiom of psycho-physical intimacy; you and your brain are inseparable, why separate them linguistically? Hacker says that "it makes no sense to speak of the brain containing knowledge or information written in its own language". On the contrary, neuroscientists are beginning to give good sense to that statement. Jeffrey Gray has no doubts: "all human languages are stuffed full of rules. . . . The rules, then, must be contained in the heads of those speakers and hearers".

The linguist Harris might ask "Which rules?", because grammars are embarrassingly numerous. How do you hope to find them in the brain when linguists do not know what they are? One must agree that scientists when speaking of a 'language' do not consider all the subtle problems that have arisen since de Saussure discussed the difference between 'langage' and 'langue'. There are difficulties in the use of such terms as 'information', 'coding' and 'representation' and we try to define them in general biological terms, as I have done more recently in my book Philosophy and the Brain. It is unsurprising that such changes of use upset those who do not look at the whole living world, but it is disappointing that the critics show so little understanding when one hoped for help with common problems.

Surely a wider view will help with the classic problem of the mental and the physical. Harris believes that neuroscientists "do not wish to be restricted by accepting the traditional distinction between 'brain' and 'mind'" and he claims that the motivation of the biologist is that he "wants to be in on the act when it comes to solving these ultimate scientific mysteries: how do human beings think? and what is thought?". This is an unworthy tone for one scholar to adopt of others who are working in an obviously related subject. Most neuroscientists do indeed feel that a re-consideration is necessary. In a wise article, Paul Seabright discusses the "tensions that arise between the mind we experience and as explained by science". For one thing "the physical world is everywhere; it has no pockets into which non-physical objects could fit.

But most of us also think many things that exist are not just physical objects". So how are we to describe this property of mentality that attaches to ourselves and perhaps at least to some animals?

The first essential is not to separate the aspects too widely. Stephen Clark echoes Seabright on this: "a surprising number of people still seem to think that offering an explanation in terms of intention and feelings or the like is somehow incompatible with an explanation in terms of physiological conditions, as if intention occupied space to the exclusion of nerve fibres". Ted Honderich presses the point that "Neuroscience... must change the philosophy of mind . . mainly because it establishes the axiom or proposition of psycho-physical imtimacy". He goes on with his suggestion of how we should formalize this co-occurrence: "Consciousness, truly described by the metaphor of the interdependent subject and object, does exist". He characterizes their relationship as one of nomic (law-like) connection. Nicholas Humphrey uses a different metaphor: "consciousness is in fact a picture of the workings of the brain".

Euan Macphail, a psychologist, asks "When we solve problem $\mathrm{X}$, what processes are taking place in our minds (or brains)?". This has the unfortunate effect of suggesting that the mind is somehow an entity that can contain processes. Surely, as Ayer has said, "We do not need to conceive of minds as substances, or indeed as entities of any kind". It is better to say with Colin McGinn, "Still, the brain is a physical entity and it is conscious, so it must have some design feature, presumably 'physical' in nature (whatever that might mean), that makes it conscious". But, he continues, "we do not at present know what that feature is, and so we do 